\title{
Subcellular localization of L-selectin ligand in the endometrium implies a novel function for pinopodes in endometrial receptivity
}

Reza Nejatbakhsh ${ }^{1}$, Maryam Kabir-Salmani ${ }^{2,3^{*}}$, Eva Dimitriadis ${ }^{4}$, Ahmad Hosseini $^{3}$, Robabeh Taheripanah ${ }^{5}$, Yousef Sadeghi ${ }^{1}$, Yoshihiro Akimoto ${ }^{6}$ and Mitsutoshi Iwashita ${ }^{7}$

\begin{abstract}
Background: Apical surfaces of human endometrial epithelium and endothelium are key elements for the initiation of molecular interactions to capture the blastocyst or leukocyte, respectively. The L-selectin adhesion system has been strongly proposed to play an important role in the initial steps of trophoblast adhesion and promotion of integrin-dependent processes, ultimately culminating in the establishment of the embryo-maternal interface. On the basis of these facts, we hypothesized a novel role for pinopodes as the first embryo-fetal contact sites to contain the highest subcellular expression of L-selectin ligand suggesting its role in early adhesion as predicted. Thus, the objective of this study was therefore to determine the subcellular pattern of distribution of the L-selectin ligand (MECA-79) in human endometrial apical membrane region during the window of implantation.
\end{abstract}

Methods: Endometrial biopsies of secretory phases from fertile females ranging in age between 25 and 42 years were studied using several approaches, including scanning electron microscopy (SEM), immunostaining for light microscopy and transmission electron microscopy (TEM), and immunoblotting as well as statistical analysis of the area-related numerical densities of immunoreactive MECA-79-bound nanogolds to detect the expression pattern and the subcellular distribution pattern of L-selectin ligand (MECA-79) in human endometrium during the window of implantation.

Results: The endometrial biopsies were scored according the dating criteria of Noyes et al. by an experienced histologist. The SEM images of the midluteal phase specimens revealed that fully developed pinopodes were abundant in our samples. HRP-immunostaining and immunofluorescent staining as well as immunoblotting revealed that MECA-79 was expressed in the midluteal phase specimens. The results of immunogold TEM illustrated the expression of MECA-79 in human pinopodes in the midluteal phase and a higher area-relate numerical density in pinopodes compared to that of the uterodome-free areas.

Conclusions: This is the first demonstration of the subcellular localization of MECA-79 in the human pinopodes which may indicate a novel role for pinopodes to be capable of shear-stress-dependent tethering-type adhesion in the initial phases of human embryo implantation.

Keywords: Endometrium, Uterodome, Implantation, MECA-79, L-selectin Ligand, Pinopode

\footnotetext{
* Correspondence: maryam@nigeb.ac.ir

${ }^{2}$ Molecular Genetics Department, National Institute of Genetic Engineering

and Biotechnology, Tehran, Iran

${ }^{3}$ Cellular and Molecular Biology Research Center, Medical School of Shaheed

Beheshti University of Medical Sciences, Tehran, Iran

Full list of author information is available at the end of the article
} 


\section{Background}

In humans, there is a distinct 'window of implantation' during the midluteal phase when the endometrium demonstrates maximal receptivity for embryo implantation [1]. There is convincing data that the uterine luminal epithelium is central in controlling receptivity, and probably acting initially as a barrier to challenge attaching embryo [2]. Several candidate adhesion molecules are expressed in the luminal epithelium of receptive endometrium where they are thought to facilitate embryo apposition/adhesion/ communication to the endometrium [3-5]. However, because of difficulties in analyzing these processes in human models, differences among primate species [6,7], the lack of suitable experimental models, and significant variations between rodent and human models of embryo implantation [1], the exact molecular basis of these initial interactions remain to be discovered.

Considering the fact that the human embryo must attach itself to the uterus under conditions of shear stress similar to that of leukocyte transmigration, numerous investigators have proposed that the molecular basis between implantation and leukocyte transmigration should bear some similarities. Several investigators have demonstrated that L-selectin and its oligosaccharide ligands, which constitute L-selectin adhesion system, could be considered as one of the most important candidate pathways to mediate the initial embryo-maternal interactions $[8,9]$. In support, it was recently demonstrated that human blastocysts express L-selectin on their external surfaces [10] raising the possibility that these molecules may participate in the early stages of human blastocyst attachment. Furthermore, the lack of detection of Lselectin at stages earlier than the embryonic blastocyst stage and L-selectin's intense immunostaining on the trophectoderm during hatching, indicates that this cell surface protein is developmentally regulated [11]. This was correlated with complementary increased expression of its ligand within the luminal epithelium during the mid-secretory phase $[10,12]$. Immunolocalization studies on normal endometrium have demonstrated that the Lselectin carbohydrate ligand MECA-79, antibody that recognizes L-selectin high-affinity ligands, is upregulated from the day of ovulation to day 6-post ovulation, and by comparison is reduced throughout the follicular phase or in ovulatory cycles $[10,12,13]$. More interestingly, a significant difference between the expression of L-selectin ligands between fertile and infertile women was reported and the MECA-79 epitopes were shown to be expressed at a higher level in fertile compared to that of infertile patients $[14,15]$. Other than embryo implantation $[10,16]$, this adhesion system correlates with many physiological and pathological processes including leukocyte infiltration [17,18], lymphocyte homing [19], and tumor metastasis [20,21] indicating the existence of similar pathways between these processes. Since the apical surface of the endometrium contains key elements for the initiation of molecular interactions between human blastocysts and the endometrium, and that the L-selectin ligand adhesion system is believed to play a major role in mediating initial embryonic apposition and adhesion, this prompted us to investigate the subcellular localization of L-selectin ligand at the pinopodes, the most apical surfaces of the receptive endometrium [22], and the first embryo-maternal contact sites. In the present study, we proposed that pinopodes may have a novel function in the unusual cell-cell interactions that take place in the early steps of human embryoendometrial apposition/adhesion similar to that of tethering of blood cells.

\section{Methods}

\section{Endometrial biopsy specimens}

Endometrial biopsies were obtained during secretory phases were collected by curettage from the anterior wall of the uterine cavity of women (ages 25-42) undergoing minor gynecological investigations unrelated to endometrial pathology. All women were fertile with regular menstrual periods (25-35 days) and none of them had used steroidal contraceptives or intrauterine devices for at least 3 months prior to the sampling. All patients gave their informed consent for the collection and investigational use of endometrial tissues. This study was approved by the local Ethical Committee and Southern health Human Research Ethics Committee, (\#09317B), Monash Medical Centre, Clayton, Victoria (cell culture experiments) and Shaheed Beheshti Medical Sciences University Ethical Committee, (\#88-01115-6367-3144), Tehran-Iran (all other experiments). Eight patients were tested for our experiments, 3 patients for immunoblotting and 5 patients for all other experiments. Except immunoblotting biopsies, another biopsies from each patient were divided to several small portions to be used for light microscopy, immunohistochemistry, scanning electron microscopy (SEM) and immunogold staining of transmission electron microscopy (TEM) experiments. For endometrial dating, samples were fixed in $10 \%$ neutrally buffered formaldehyde and the paraffin-embedded biopsies were stained with hematoxylin and eosin and evaluated by an experienced observer according to the histopathological criteria of Noyes [23]. Samples used for cell culture and western blot analysis were collected in a 1:1 mixture of DMEM and Ham's F12 medium (DMEM/F12; Trace Biosciences, Sydney, Australia) supplemented with $1 \%$ penicillin, streptomycin, and fungizone (Common Wealth Serum Laboratories, Melbourne, Australia) and Lglutamine (Sigma Diagnostics, St. Louis, MO). 
Culture of primary human endometrial epithelial cells and human endometrial epithelial (HES) cell line

Fresh samples were transferred in a 1:1 mixture of DMEM/F12 supplemented with $1 \%$ penicillin, streptomycin, and fungizone and L-glutamine to culture room and washed three times. Human endometrial tissues were digested with collagenase type $3,0.2 \mathrm{mg} / \mathrm{ml}$ for 20 min 2 times and the suspension was filtered through 43 and $11 \mu \mathrm{m}$ nylon mesh to collect endometrial epithelial fragments, as previously described work [24]. Briefly, the epithelial fragments were collected and re-suspended in a 1:1 mixture of DMEM/Hams F-12 (F12; Thermo Electron Corp., Melbourne, Australia) supplemented with $10 \%$ fetal calf serum (FCS; Invitrogen, Carlsbad, CA), 2 mM L-glutamine (Thermo Electron), and $1 \%$ antibiotic antimycotic solution (Life Technologies, Inc., Auckland, New Zealand) and plated. Endometrial epithelial cells were collected from the filter paper and cells were further purified by selective adherence. Epithelial cells were allowed to grow out from glandular structures for $48 \mathrm{~h}$, then detached with trypsin, and serially replated (three times) in plastic culture dishes for 30 min each time, to allow adherence of contaminating stromal cells. Non-adherent cells were transferred to 24well plates and were allowed to grow out for $48 \mathrm{~h}$. Cells were grown in DMEM/F12/charcoal-stripped fetal calf serum for $48 \mathrm{~h}$ until $80 \%$ confluent. This method achieves cultures of $85-90 \%$ epithelial cell purity, as judged by morphological and immunohistochemical criteria [25]. A pan-cytokeratin antibody (Dako) diluted 1:4 in non-immune block after enzymatic antigen retrieval $\left(0.1 \%\right.$ trypsin in $0.1 \% \mathrm{CaCl} 2$ for $15 \mathrm{~min}$ at $\left.37{ }^{\circ} \mathrm{C}\right)$ were used for immunohistochemical staining.

For the extended experiments in which insufficient primary EECs were available, a human endometrial epithelial (HES) cell line were used. The HES cell line [26] was obtained from Dr. Douglas Kniss (Ohio State University, Columbus, OH). Cells were maintained in RPMI 1640 (Thermo Electron) supplemented with $10 \%$ FCS. Confluent cells were transferred into serum reduced (1 \% FCS) medium for $24 \mathrm{~h}$ before use.

\section{Scanning electron microscopy (SEM)}

SEM was performed to evaluate the presence of pinopodes in the endometrial specimens obtained at the midluteal phase of the menstrual cycle. For SEM preparation, endometrial biopsies were fixed for at least $24 \mathrm{~h}$ in $2.5 \%$ glutaraldehyde in $0.1 \mathrm{M}$ phosphate buffer ( $\mathrm{pH} 7.4$ ) at $4{ }^{\circ} \mathrm{C}$ and postfixed using $1 \% \mathrm{OsO}_{4}$ in $0.1 \mathrm{M}$ phosphate buffer ( $\mathrm{pH}$ 7.4) for $1 \mathrm{~h}$. The specimens were then dehydrated in a graded series of ethanol (50\%, $70 \%$, $90 \%, 99.5 \%$ and $100 \%$ ), critical-point-dried with carbon dioxide using a freeze drying device (JFD-300, JEOL, Tokyo, Japan), mounted, and coated with gold in a sputter coater. Finally, the specimens were observed under a scanning electron microscope (JSM- 5600 LV SEM, JEOL).

\section{Immunohistochemistry and immunofluorescent staining for light microscopy}

Polymer peroxidase staining (Envision+/HRP; DakoCytomation, Denmark) was performed as described previously [27]. Briefly, using optimal cutting temperature (OCT) compound-embedded samples, cryostatic sections (4 $\mu \mathrm{m}$ thickness) were mounted on positively charged slides, fixed with ice-cold $100 \%$ acetone for 10 minutes and air-dried. After blocking endogenous peroxidase activity by immersing the slides in $0.3 \%$ hydrogen peroxide $\left(\mathrm{H}_{2} \mathrm{O}_{2}\right)$ in methanol for 10 minutes at room temperature, nonspecific background was blocked with $5 \%$ BSA for 30 minutes at room temperature. The tissue sections were then incubated overnight at $4{ }^{\circ} \mathrm{C}$ with an anti-human L-selectin ligand monoclonal antibody (MECA-79; BD Pharmingen) at a concentration of $2 \mu \mathrm{g} / \mathrm{ml}$ and isotype IgG control at the same concentration as the primary antibody. After washing, sections were incubated with an Envision+/HRP anti-mouse secondary IgG for $30 \mathrm{~min}$ at room temperature. Peroxidase activity was detected by incubating the specimens for about $10 \mathrm{~min}$ at room temperature with $0.5 \mathrm{mg} / \mathrm{ml}$ DAB-0.005 \% $\mathrm{H}_{2} \mathrm{O}_{2}$ PBS. Finally, nuclear counterstaining was done with hematoxylin. A positive control section of tonsil and a negative (no antibody) control section of endometrium tissue were used to determine the specificity of the antibody.

For immunofluorescent staining, cryostatic sections were fixed with ice-cold $100 \%$ acetone for 10 minutes and air-dried. Nonspecific background was then blocked with $5 \%$ BSA for 30 minutes at room temperature. The tissue sections then were incubated overnight at $4{ }^{\circ} \mathrm{C}$ with $2 \mu \mathrm{g} / \mathrm{ml}$ of an anti-human L-selectin ligand monoclonal antibody (MECA-79). For negative controls, normal mouse serum IgG was used instead of primary antibody. The tissue sections were then counter-stained with appropriate secondary antibody (FITC-labeled IgG, $2 \mu \mathrm{g} / \mathrm{ml}$ ) and incubated for $1-3 \mathrm{~h}$ at room temperature. Tissue sections were washed with PBS, rinsed in deionized water and mounted. The tissue sections were then observed using an AX-80 fluorescence microscope (Olympus Optical).

\section{Immunostaining for transmission electron microscopy (TEM)}

Immunogold staining for TEM was performed to determine the ultrastructural distribution of L-selectin ligand (MECA-79) according to previous reports [27]. Briefly, specimens were divided into the $2 \mathrm{~mm}^{3}$ blocks and fixed in $4 \%$ PFA in $0.1 \mathrm{M}$ phosphate buffer ( $\mathrm{pH}$ 7.4) for at 
least $24 \mathrm{~h}$ at $4{ }^{\circ} \mathrm{C}$. After dehydration in a graded series of ethanol (50\%, $70 \%, 90 \%, 99.5 \%, 100 \%)$, they were embedded in Lowicryle white resin (London Resin company Ltd., London, UK). They were cut into ultrathin sections, which were then washed in PBS and pretreated with $5 \%$ BSA for $10 \mathrm{~min}$ at room temperature. After rinsing in PBS, they were incubated overnight at $4{ }^{\circ} \mathrm{C}$ with a monoclonal anti-human L-selectin ligand antibody (MECA-79, $1.5 \mu \mathrm{g} / \mathrm{ml}$ ) or with normal mouse sera $(1.5 \mu \mathrm{g} / \mathrm{ml})$, as negative control. Following washing in PBS (5 times, $5 \mathrm{~min}$ each), the ultrathin sections were incubated overnight at $4{ }^{\circ} \mathrm{C}$ with $12 \mathrm{~nm}$ colloidal goldconjugated secondary (Jackson Immuno Research Laboratories Inc., West Grove, PA, USA), diluted with PBS (1:20). The ultrathin sections were then washed in PBS followed by washing in distilled water. The ultrathin sections were stained with uranyle acetate and observed under a transmission electron microscope (JEM-1010; JEOL, Japan).

Morphometric and statistical analyses were performed to determine the expression pattern of MECA-79 during the opening of the implantation window, that is, days 19-20 of a normal menstrual cycle. For morphometric analysis, 400 fields obtained at the midluteal phase (40 fields for each biopsy specimen, each field equaled to 8.04 $\mu^{2}$ ) were randomly chosen near the cell membrane of either pinopodes or the neighboring uterodomefree areas by an observer who was blind to the identity of the grids. Then, the number of immunogold particles was counted in all selected areas at the same magnification (X15000). After calculating the area-related numerical densities of immunogold particles, statistical analysis was performed comparing pinopodes and the neighboring uterodome-free areas. For the morphometric assessment of the area-related numerical densities of immunogoldconjugated MECA-79, statistical analysis was carried out by taking the mean number of immunogold particles in 40 fields per block of each specimen from 5 patients' endometrial biopsies. The area-related numerical density of immunogold particles was expressed as Mean \pm SEM. Statistical significance was evaluated using paired sample t- test and a $p<0.05$ was considered statistically significant.

\section{Immunoblotting}

Immunoblotting was performed for expression studies of MECA-79. Both endometrial epithelial cell line (HES) and primary human endometrial epithelial cells (hEEC) were used and western blot analyses were performed using standard protocols as previously described [28]. Briefly, equal amounts of protein lysate $(10 \mu \mathrm{g})$ were separated on 8.5 \% SDS/PAA gels and transferred onto polyvinylidene difluoride membranes (Hybond-P; Amersham Pharmacia Biotech, Piscataway, NJ). All membranes were incubated with Ponceau-S (Sigma) to ensure equal protein loading in all lanes. After blocking with $5 \%$ nonfat dry milk in TBS with $0.1 \%$ Tween-20 (Bio-Rad Laboratories, Hercules, $\mathrm{CA})$, membranes were incubated overnight $\left(4^{\circ} \mathrm{C}\right)$ with rat monoclonal antibody MECA-79 (200 $\mu \mathrm{g} / 0.1 \mathrm{ml}, 1: 500$, Santa Cruz, SC 19602 L). After washing with $0.2 \%$ Tween-20/TBS, the membranes were incubated $1 \mathrm{~h}$ (room temperature) with secondary antibodies (rabbit anti rat IgG horseradish peroxidase linked, Cell Signaling Technology, Beverly, MA, 1:2500) signals were developed by using ECL Western blotting detection system (Pierce, Rockford, IL, USA) followed by the exposure of the membranes to a Kodak X-AR film (Eastman Kodak co., Rochester, NY, USA) for 1-5 min at room temperature. To analyze nonspecific secondary antibody binding, membranes were stripped and incubated with isotype control rat IgG (Sigma, Chemical Company, St. Louis, MO, $1.7 \mathrm{mg} / \mathrm{ml}$ ). Page Ruler prestained protein ladder (Fermentas, St. Leon-Rot, Germany) was used as a molecular size marker. This experiment was performed in triplicate using three different samples obtained at the midluteal phase.

\section{Results}

SEM images demonstrated that the endometrial luminal epithelium in the midluteal phase of the menstrual cycle showed two different types of cells: ciliated and nonciliated cells. The majority of the luminal epithelial cells were of the latter type (Figure $1 \mathrm{~A}$ and $\mathrm{B}$ ). The membranous projections on the apical pole of nonciliated cells appeared as fine microvilli and were dome-like. The SEM images of the midluteal phase specimens revealed that fully developed pinopodes were abundant in these samples among few regressing pinopodes (Figure $1 \mathrm{~A}$ and $\mathrm{B})$.

Strong immunoreactivity for MECA-79 was seen in the midluteal phase human endometrium (Figure 2A). MECA-79 localized at the luminal and glandular epithelium predominantly at the cell membrane with little cytoplasmic staining observed. By contrast, no MECA-

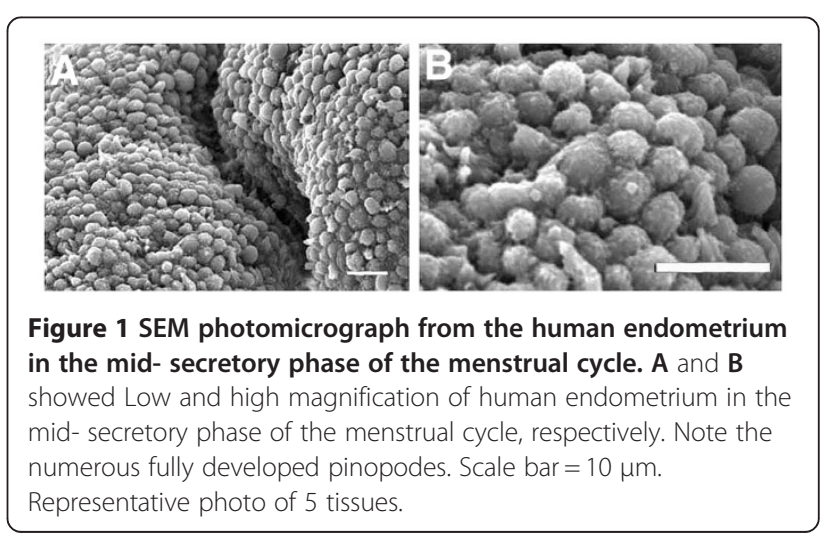




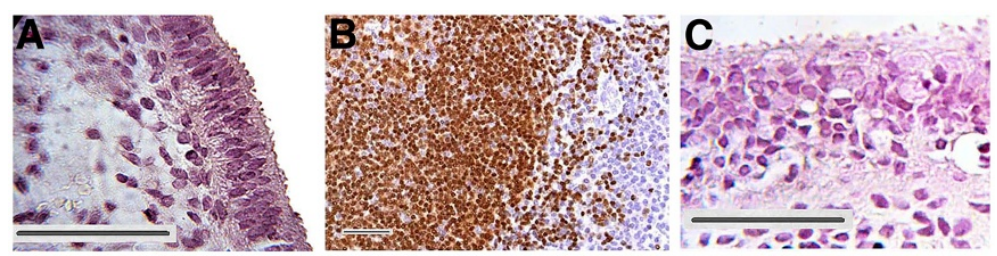

Figure 2 Immunolocalization of L-selectin ligand. Positive staining for L-Selectin ligand showed as brown pigment. (A) Mid-secretory phase of human endometrium, (B) tonsil as positive control (C) negative control. Scale bars $=50 \mu \mathrm{m}$. Representative photo of 5 tissues.

79 immunostaing was visible in the stroma. Section of tonsil was used as positive control demonstrated immunoreactivity for MECA-79 (Figure 2B). In the negative controls, no staining was observed (Figure $2 \mathrm{C}$ ).

Similarly immunofluorescent staining revealed MECA79 localized predominantly at luminal epithelium in the midluteal phase human endometrium (Figure 3A). In the negative controls, no staining was observed (Figure 3C).

Immunoblotting analysis demonstrated the expression of L-selectin ligand in both epithelial endometrial cells (EEC) and human endometrial epithelial cell line (HES) in protein level (Figure 4), while no expression was seen in negative controls using rat IgG as isotype control.

In the immunogold TEM photomicrographs, MECA79-conjugated nanogolds were predominantly observed in the pinopodes (Figure 5A, 5B), implicating a different subcellular area-related expression pattern of MECA-79 in the luminal epithelial cells of the midluteal phase endometrium (Figure 5B). In the negative controls, no staining was observed (Figure 5C).

Semi-quantitative statistical analysis revealed that the area-related numerical densities of the MECA-79conjugated nanogolds were 3.9 higher in pinopodes compared to that of pinopode-free neighboring areas (Figure 6).

\section{Discussion}

To the best of our knowledge, this is the first report of the subcellular localization of L-selectin ligand MECA79 in the human pinopodes suggest a novel role for pinopodes possibly in inducing a shear-stress-dependent tethering-type adhesion in the initial phases of human embryo implantation. It has been reported that pinopodes are integrin-enriched subcellular structures that can be considered as biomarkers of endometrial receptivity [29]. However, the clinical usefulness of pinopodes to delineate a period of endometrial receptivity seems unlikely following recent findings that pinopodes have a prolonged ( $>5$ days) presence in the luteal phase and fail to delineate the brief (24-48 h) window of receptivity [30]. Therefore, the functional importance of pinopodes, bleb-like hormone-dependent structures that appear at the time of implantation and extend beyond the glycocalyx layer of the apical membrane of the endometrial epithelium, remains elusive $[31,32]$. Endometrial pinopodes resemble morphologically the docking structures of the endothelium [22] that are believed to be key elements for the initiation of molecular interactions to capture the blastocyst or leukocyte, respectively, indicating an active role for adhesive three dimensional docking structures in the extravasation sequence corresponds to the interaction of selectins with their carbohydrate-based ligands [33-35]. Thus, an objective of this study was to detect the existence of a member of such systems at pinopodes.

To this end, MECA-79, a monoclonal antibody that blocks L-selectin-dependent lymphocyte attachment and recognizes 6-sulfo sLex, a sulfation dependent determinant on L-selectin ligands $[36,37]$ was used to determine the subcellular distribution pattern of the L-selectin ligand in human endometrial epithelial cells and in pinopodes. The antibody binds the sulfated oligosaccharide epitopes of L-selectin ligands, enabling the quantification of L-selectin expression in represented tissue samples $[38,39]$. The evaluation of the expression pattern of Lselectin ligand was based on a semi quantitative
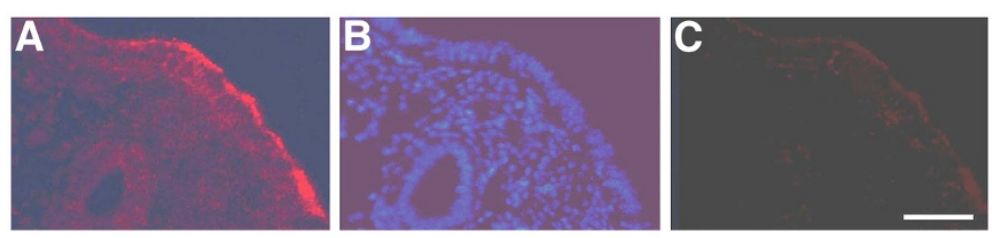

Figure 3 Immunofluorescent images of L-Selectin ligand. Human endometrial biopsies obtained from midluteal phase of a normal menstrual cycle. Red colour showed L-Selectin ligand positive fluorescent (A) Blue colour demonstrated nucleus staining by DAPI (B), negative control (C). Scale bar $=50 \mu \mathrm{m}$ and representative for Figures A-C. A-C is representative photos of 5 tissues. 


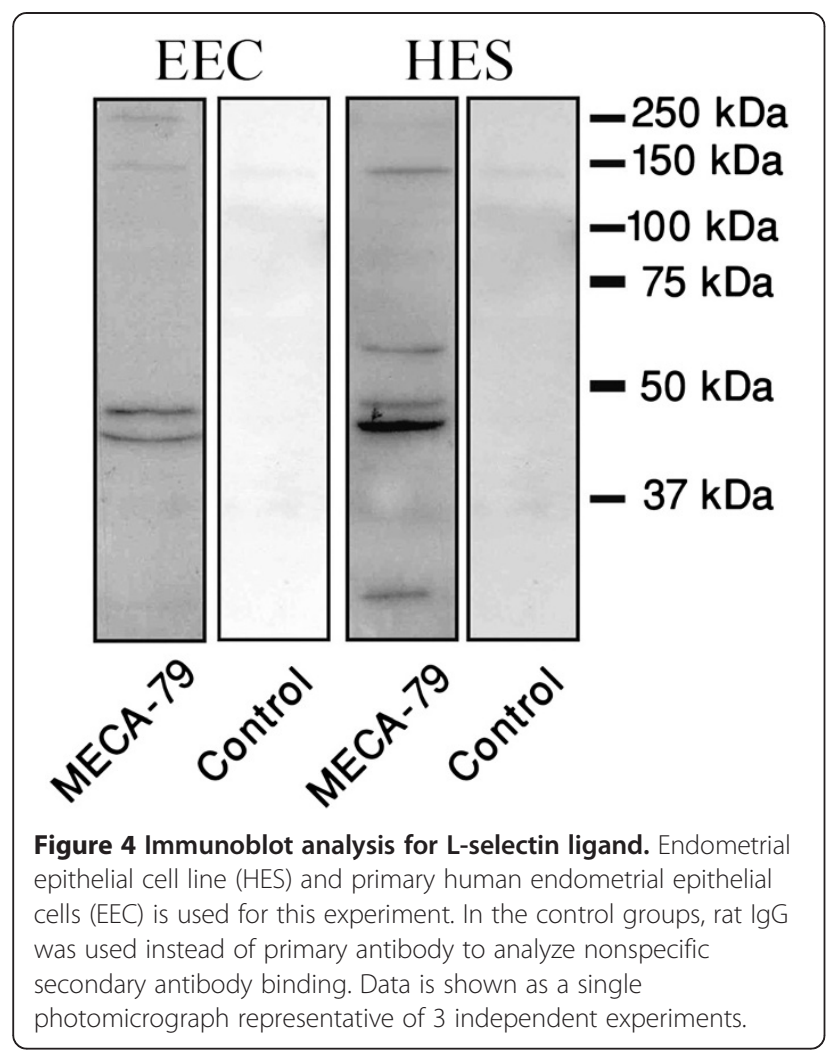

immunohistochemical score, incorporating morphometric analysis of area-related numerical density of MECA79-conjugated nanogolds in pinopode and adjacent pinopode-free areas of apical cell membrane of luminal endometrial epithelium. Meca-79 immunostainings demonstrated that MECA-79 localized at the luminal and glandular epithelium predominantly at the cell membrane with little cytoplasmic staining observed (Figure 2, panel b). By contrast, no MECA-79 immunostaing was visible in the stroma. This is inconsistent with a previous report which showed that in the glandular epithelium the expression of L-selectin ligands was greatest in the midluteal phase [12]. Western blot analysis also showed that L-selectin ligand protein was detected in endometrial epithelial culture of our endometrial epithelial cell line (HES) as well as in primary endometrial epithelial cells. These results demonstrated the presence of L-selectin ligand in the human endometrial epithelial cells, supporting our immunostaining results and were consistent with pervious publications in cultured endometrial epithelial cells $[10,15]$. Moreover, the results of our TEM immunogold staining demonstrated the expression of MECA-79 at pinopodes of mid-secretory endometrial biopsies. The semi quantitative morphometric analysis revealed that statistically higher area-related numerical density of MECA-79-conjugated nanogolds exists in

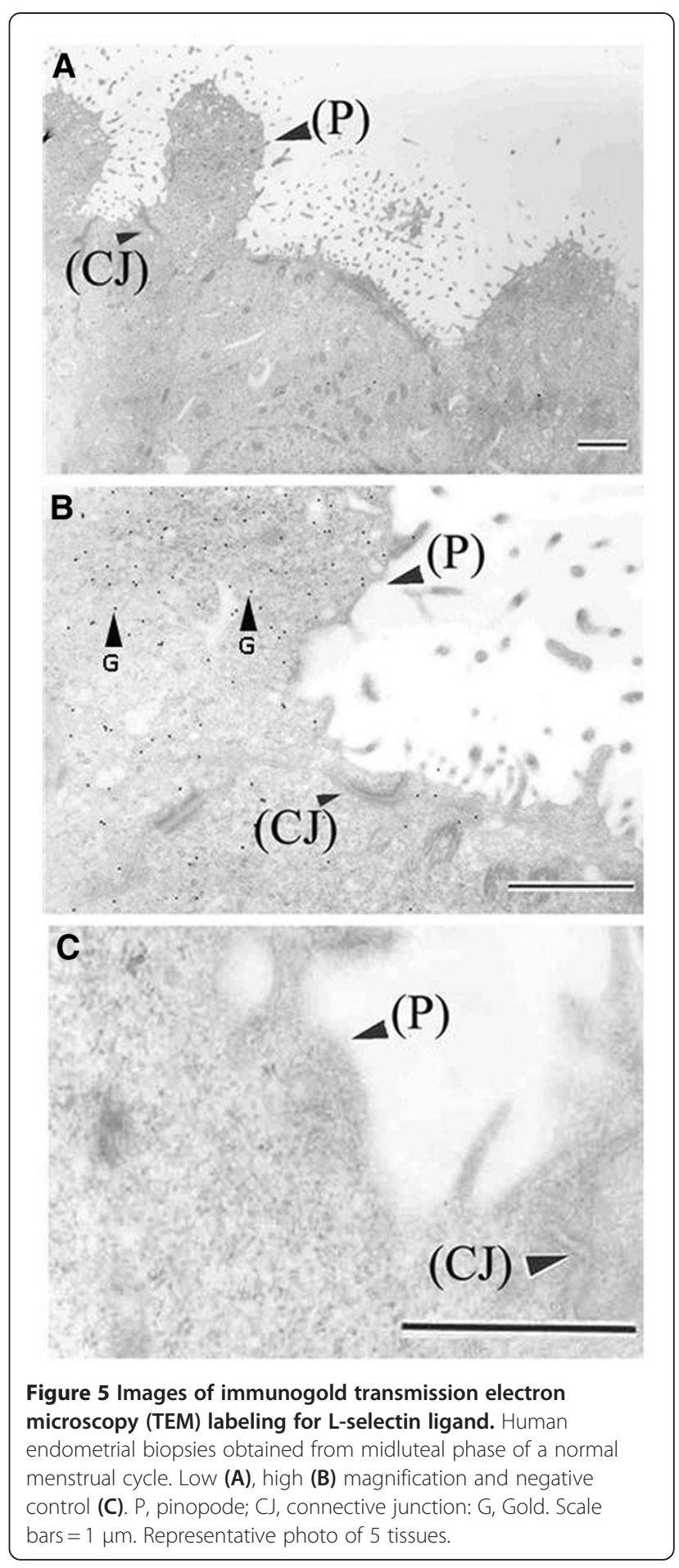

pinopode compared to that of adjacent pinopode-free areas. This is, to our knowledge, the first report of subcellular and distribution pattern of L-Selectin ligand in human luminal endometrial epithelium. These results can propose a novel role for human endometrial pinopodes similar to that of endothelial docking structures in 


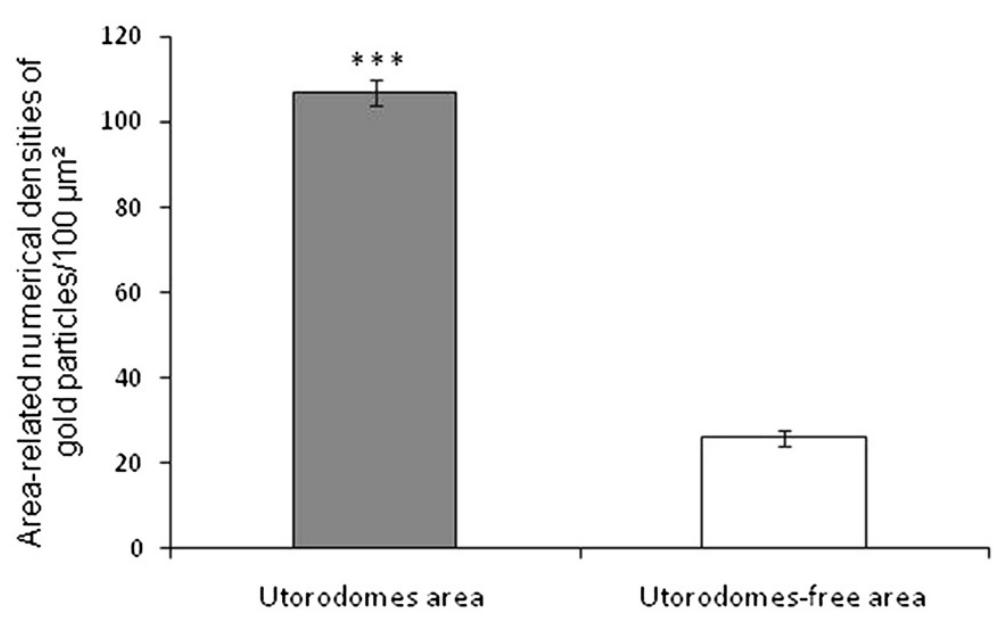

Figure 6 Statistical analysis of the area- related numerical densities of immunogold conjugated L-Selectin ligand in human midsecretory phase endometrial biopsies. The statistical analyses of the number of immunogold particles revealed that the distribution of $L$ Selectin ligand in these specimens was significantly $(p<0.001)$ higher in the pinopodes of the mid-secretory phase specimen compared to pinopode- free areas. ${ }^{* * *}: p<0.001$.

tethering process which allows the leukocyte to roll on the endothelial cell wall. It seems that the L-selectin adhesion system plays a role in human, but not mouse embryo implantation. It is reasonable that mutant mice deficient in the L-selectin gene show no defect in implantation even though a microarray analysis of mouse blastocysts has showed an elevation of L-selectin transcripts during the maturation stage, when the blastocysts are competent for implantation [40]. Thus, it might be concluded that other selectins or integrin ligands compensate for this deficiency in mice or the role of $\mathrm{L}$-selectin in implantation is restricted to humans.

E-, L-, and P-selectin were originally thought to be expressed exclusively by hemangioblast descendents [9] and the discovery that the L-selectin system might function during reproduction was an unexpected finding. Our data together with previous reports may reveal that a clear parallelism between the different steps in human embryo-endometrial apposition/adhesion and leukocyteendothelium rolling/adhesion can be established both at the molecular and morphological levels. Such homotypic adhesive interaction using the L-selectin adhesion system has been previously suggested by the other groups for placental cytotrophoblast [41,42]. They have a remarkable ability to modulate their adhesion molecule repertoire as they move through cell columns and acquire the ability to invade the uterine wall and the blood vessels that traverse this region. Of course, a large force is required to physically immobilize a free-floating cell to a flat surface. Given the enormous difference in size between a human blastocyst (diameter, $115 \sim 265 \mathrm{~mm}$ ) and lymphocyte (diameter, $10 \mathrm{~mm}$ ), it is difficult to imagine that a blastocyst could be immobilized to endometrial epithelia solely through L-selectin, given the somewhat weak selectin-carbohydrate interactions $[43,44]$. It seems reasonable to speculate that a human blastocyst rolls over the glycocalyx of the endometrial epithelium through weak interactions with L-selectin, similar to the movement of lymphocytes over endothelial cells that is mediated by L-selectin. L-selectin-mediated rolling may allow cross-talk between the blastocyst and maternal epithelia, leading to stronger cell adhesion by direct binding between the components embedded in the plasma membranes on the fetal and maternal sides. Considering the report that showed pinopode formation is accompanied by loosening of endometrial inter epithelial cell contacts strengthens our hypothesis that the expression of L-selectin ligand in pinopodes and the activation of L-selectin ligand-mediated rolling might facilitate stronger blastocyst attachment and penetration to the lateral membrane of endometrial epithelial cells. This is consistent with a previous suggested model for human embryo adhesion phases, termed as early and late adhesion events [45]. Moreover, previous studies showed that mucin-1 (Muc-1), a cell-surface glycoprotein expressed on pinopodes, carries both sLex and MECA-79 epitopes [46,47], although another study indicates that MUC1 is expressed on ciliated cells [48]. As the presence of $\mathrm{L}$ - selectin ligand is not restricted to the ciliated cells $[10,12,13,15]$, it seems that MUC1 is one of the carriers of L- selectin ligand in human endometrium [45]. MUC1 is a large, transmembrane mucin glycoprotein abundantly expressed at the apical surface of uterine epithelia in all species examined to date. Loss of MUC1 at the time of embryo implantation occurs in many species; however, this does not appear to be the case in 
humans, suggesting that the human endometrium actively prevents the embryo from adhering except at the very spot of implantation. Selectins are proposed to have an important role in this phase to ensure suitable rolling of the blastocyst to ensure that the blastocyst will settle in the proper position and in the correct orientation.

\section{Conclusions}

In conclusion, this study highlights the potential importance of pinopodes in the early steps of human embryoendometrial apposition/adhesion and identities a possible novel role for pinopodes in human implantation. It provide evidence for the concept that trophoblast/ endometrium may use the L-selectin adhesion system to carry out a type of tethering adhesion that facilitates homotypic rather than heterotypic interactions demonstrating a relative abundance of L-selectin ligands presented in endometrial pinopodes.

\section{Competing interests}

The authors declare that they have no competing interests.

\section{Acknowledgements}

We thank Dr Stefan Sonderegger for assistance with the Western blot methodology. This work is supported by a grant from National Institute of Genetic Engineering and Biotechnology and Shaheed Beheshti University of Medical Sciences to MKS (It is part of Ph.D student thesis Reza Nejatbakhsh in Shaheed Beheshti University of Medical Sciences, Tehran, Iran). ED is the funding recipient of an NHMRC fellowship \#550905 and project grant \#388901. ED was supported by the Victorian State Government Operational Infrastructure Support and Australian Government NHMRC IRIISS.

\section{Author details}

'Biology and Anatomy Department, Medical School, Shaheed Beheshti University of Medical Sciences, Tehran, Iran. ${ }^{2}$ Molecular Genetics Department, National Institute of Genetic Engineering and Biotechnology, Tehran, Iran. ${ }^{3}$ Cellular and Molecular Biology Research Center, Medical School of Shaheed Beheshti University of Medical Sciences, Tehran, Iran. ${ }^{4}$ Embryo Implantation Laboratory, Prince Henry's Institute of Medical Research, Melbourne, Australia. ${ }^{5}$ Infertility and Reproductive Health Research Center, Shaheed Beheshti University of Medical Sciences, Tehran, Iran. ${ }^{6}$ Department of Anatomy, Kyorin University School of Medicine, Tokyo, Japan. ${ }^{7}$ Department of Obstetrics and Gynecology, Kyorin University School of Medicine, Tokyo, Japan.

\section{Authors' contributions \\ RN performed cell cultures, Western blot, immunohistochemistry, and assisted in drafting the manuscript. MKS and ED conceived the study, designed, and participated in data analysis and drafted the manuscript. $\mathrm{AH}$ and $\mathrm{Ml}$ designed and provided assistance in co-ordination of the study. RT prepared ethical approval, recruited patients and collected samples. YA and YS developed the SEM and TEM assays. All authors critically analysed the manuscript and approved the final manuscript.}

Received: 24 January 2012 Accepted: 15 June 2012 Published: 15 June 2012

\section{References}

1. Carson DD, Bagchi I, Dey SK, Enders AC, Fazleabas AT, Lessey BA, Yoshinaga K: Embryo implantation. Dev Biol 2000, 223:217-237.

2. Achache $H$, Revel A: Endometrial receptivity markers, the journey to successful embryo implantation. Hum Reprod Update 2006, 12:731-746.

3. Aplin JD: Adhesion molecules in implantation. Rev Reprod 1997, 2:84-93.

4. Dey SK, Lim H, Das SK, Reese J, Paria BC, Daikoku T, Wang H: Molecular cues to implantation. Endocr Rev 2004, 25:341-373.
5. Staun-Ram E, Shalev E: Human trophoblast function during the implantation process. Reprod Biol Endocrinol 2005, 3:56.

6. Enders AC, Blankenship TN: Modification of endometrial arteries during invasion by cytotrophoblast cells in the pregnant macaque. Acta Anat (Basel) 1997, 159:169-193.

7. Ramsey EM, Houston ML, Harris JW: Interactions of the trophoblast and maternal tissues in three closely related primate species. Am J Obstet Gynecol 1976, 124:647-652.

8. Alon R, Feigelson S: From rolling to arrest on blood vessels: leukocyte tap dancing on endothelial integrin ligands and chemokines at sub-second contacts. Semin Immunol 2002, 14:93-104.

9. Rosen SD: Ligands for L-selectin: homing, inflammation, and beyond. Annu Rev Immunol 2004, 22:129-156.

10. Genbacev OD, Prakobphol A, Foulk RA, Krtolica AR, llic D, Singer MS, Yang ZQ, Kiessling LL, Rosen SD, Fisher SJ: Trophoblast L-selectin-mediated adhesion at the maternal-fetal interface. Science 2003, 299:405-408.

11. Campbell S, Swann HR, Seif MW, Kimber SJ, Aplin JD: Cell adhesion molecules on the oocyte and preimplantation human embryo. Hum Reprod 1995, 10:1571-1578

12. Lai TH, Shih le M, Vlahos N, Ho CL, Wallach E, Zhao Y: Differential expression of $\mathrm{L}$-selectin ligand in the endometrium during the menstrual cycle. Fertil Steril 2005, 83(Suppl 1):1297-1302.

13. Shamonki MI, Kligman I, Shamonki JM, Schattman GL, Hyjek E, Spandorfer SD, Zaninovic N, Rosenwaks Z: Immunohistochemical expression of endometrial L-selectin ligand is higher in donor egg recipients with embryonic implantation. Fertil Steril 2006, 86:1365-1375.

14. Kao LC, Germeyer A, Tulac S, Lobo S, Yang JP, Taylor RN, Osteen K, Lessey $B A$, Giudice LC: Expression profiling of endometrium from women with endometriosis reveals candidate genes for disease-based implantation failure and infertility. Endocrinology 2003, 144:2870-2881.

15. Margarit L, Gonzalez D, Lewis PD, Hopkins L, Davies C, Conlan RS, Joels L, White JO: L-selectin ligands in human endometrium: comparison of fertile and infertile subjects. Hum Reprod 2009, 24:2767-2777.

16. Fazleabas AT, Kim JJ: Development. What makes an embryo stick?. Science 2003, 299:355-356.

17. Jackson LA, Drevets DA, Dong ZM, Greenfield RA, Murphy JW: Levels of L-selectin (CD62L) on human leukocytes in disseminated cryptococcosis with and without associated HIV-1 infection. J Infect Dis 2005, 191:1361-1367.

18. Uchimura K, Rosen SD: Sulfated L-selectin ligands as a therapeutic target in chronic inflammation. Trends Immunol 2006, 27:559-565.

19. Kawashima $\mathrm{H}$ : Roles of sulfated glycans in lymphocyte homing. Biol Pharm Bull 2006, 29:2343-2349.

20. McEver RP: Selectin-carbohydrate interactions during inflammation and metastasis. Glycoconj J 1997, 14:585-591.

21. Resto VA, Burdick MM, Dagia NM, McCammon SD, Fennewald SM, Sackstein R: L-selectin-mediated lymphocyte-cancer cell interactions under low fluid shear conditions. J Biol Chem 2008, 283:15816-15824.

22. Bentin-Ley U: Relevance of endometrial pinopodes for human blastocyst implantation. Hum Reprod 2000, 15(Suppl 6):67-73.

23. Noyes RW, Hertig AT, Rock J: Dating the endometrial biopsy. Am J Obstet Gynecol 1975, 122:262-263.

24. Marwood M, Visser K, Salamonsen LA, Dimitriadis E: Interleukin-11 and leukemia inhibitory factor regulate the adhesion of endometrial epithelial cells: implications in fertility regulation. Endocrinology 2009, 150:2915-2923.

25. Marsh MM, Hampton AL, Riley SC, Findlay JK, Salamonsen LA: Production and characterization of endothelin released by human endometrial epithelial cells in culture. J Clin Endocrinol Metab 1994, 79:1625-1631.

26. Desai NN, Kennard EA, Kniss DA, Friedman Cl: Novel human endometrial cell line promotes blastocyst development. Fertil Steril 1994, 61:760-766.

27. Kabir-Salmani M, Nikzad H, Shiokawa S, Akimoto Y, Iwashita M: Secretory role for human uterodomes (pinopods): secretion of LIF. Mol Hum Reprod 2005, 11:553-559.

28. Yap J, Foo CF, Lee MY, Stanton PG, Dimitriadis E: Proteomic analysis identifies interleukin 11 regulated plasma membrane proteins in human endometrial epithelial cells in vitro. Reprod Biol Endocrinol 2011, 9:73.

29. Nardo LG, Nikas G, Makrigiannakis A, Sinatra F, Nardo F: Synchronous expression of pinopodes and alpha $v$ beta 3 and alpha 4 beta 1 integrins in the endometrial surface epithelium of normally menstruating women during the implantation window. J Reprod Med 2003, 48:355-361. 
30. Quinn CE, Casper RF: Pinopodes: a questionable role in endometrial receptivity. Hum Reprod Update 2009, 15:229-236.

31. Bentin-Ley U, Sjogren A, Nilsson L, Hamberger L, Larsen JF, Horn T: Presence of uterine pinopodes at the embryo-endometrial interface during human implantation in vitro. Hum Reprod 1999, 14:515-520.

32. Nilsson O: Ultrastructure of mouse uterine surface epithelium under different estrogenic influences. 3. Late effect of estrogen administered to spayed animals. J Ultrastruct Res 1958, 2:185-199.

33. Barreiro O, Vicente-Manzanares M, Urzainqui A, Yanez-Mo M, SanchezMadrid F: Interactive protrusive structures during leukocyte adhesion and transendothelial migration. Front Biosci 2004, 9:1849-1863.

34. Barreiro O, Yanez-Mo M, Serrador JM, Montoya MC, Vicente-Manzanares M, Tejedor R, Furthmayr H, Sanchez-Madrid F: Dynamic interaction of VCAM-1 and ICAM-1 with moesin and ezrin in a novel endothelial docking structure for adherent leukocytes. J Cell Biol 2002, 157:1233-1245.

35. Ley K, Kansas GS: Selectins in T-cell recruitment to non-lymphoid tissues and sites of inflammation. Nat Rev Immunol 2004, 4:325-335.

36. Hemmerich S, Butcher EC, Rosen SD: Sulfation-dependent recognition of high endothelial venules (HEV)-ligands by L-selectin and MECA 79, and adhesion-blocking monoclonal antibody. J Exp Med 1994, 180:2219-2226.

37. Pablos JL, Santiago B, Tsay D, Singer MS, Palao G, Galindo M, Rosen SD: A HEV-restricted sulfotransferase is expressed in rheumatoid arthritis synovium and is induced by lymphotoxin-alpha/beta and TNF-alpha in cultured endothelial cells. BMC Immunol 2005, 6:6.

38. Budwit-Novotny DA, McCarty KS, Cox EB, Soper JT, Mutch DG, Creasman WT, Flowers JL, McCarty KS Jr: Immunohistochemical analyses of estrogen receptor in endometrial adenocarcinoma using a monoclonal antibody. Cancer Res 1986, 46:5419-5425.

39. Mitsuoka C, Sawada-Kasugai M, Ando-Furui K, Izawa M, Nakanishi H, Nakamura S, Ishida H, Kiso M, Kannagi R: Identification of a major carbohydrate capping group of the L-selectin ligand on high endothelial venules in human lymph nodes as 6-sulfo sialyl Lewis X. J Biol Chem 1998, 273:11225-11233.

40. Hamatani T, Daikoku T, Wang H, Matsumoto H, Carter MG, Ko MS, Dey SK: Global gene expression analysis identifies molecular pathways distinguishing blastocyst dormancy and activation. Proc Natl Acad Sci U S A 2004, 101:10326-10331.

41. Damsky CH, Fisher SJ: Trophoblast pseudo-vasculogenesis: faking it with endothelial adhesion receptors. Curr Opin Cell Biol 1998, 10:660-666.

42. Prakobphol A, Genbacev O, Gormley M, Kapidzic M, Fisher SJ: A role for the L-selectin adhesion system in mediating cytotrophoblast emigration from the placenta. Dev Biol 2006, 298:107-117.

43. McEver RP, Moore KL, Cummings RD: Leukocyte trafficking mediated by selectin-carbohydrate interactions. J Biol Chem 1995, 270:11025-11028.

44. Richter KS, Harris DC, Daneshmand ST, Shapiro BS: Quantitative grading of a human blastocyst: optimal inner cell mass size and shape. Fertil Steril 2001, 76:1157-1167.

45. Aplin JD: Embryo implantation: the molecular mechanism remains elusive. Reprod Biomed Online 2007, 1:49-55. 14 Spec No.

46. Carson DD, Julian J, Lessey BA, Prakobphol A, Fisher SJ: MUC1 is a scaffold for selectin ligands in the human uterus. Front Biosci 2006, 11:2903-2908

47. Hild-Petito S, Fazleabas AT, Julian J, Carson DD: Mucin (Muc-1) expression is differentially regulated in uterine luminal and glandular epithelia of the baboon (Papio anubis). Biol Reprod 1996, 54:939-947.

48. Lessey BA: Two pathways of progesterone action in the human endometrium: implications for implantation and contraception. Steroids 2003, 68:809-815.

doi:10.1186/1477-7827-10-46

Cite this article as: Nejatbakhsh et al:: Subcellular localization of Lselectin ligand in the endometrium implies a novel function for pinopodes in endometrial receptivity. Reproductive Biology and Endocrinology 2012 10:46

\section{Submit your next manuscript to BioMed Central and take full advantage of:}

- Convenient online submission

- Thorough peer review

- No space constraints or color figure charges

- Immediate publication on acceptance

- Inclusion in PubMed, CAS, Scopus and Google Scholar

- Research which is freely available for redistribution

Submit your manuscript at www.biomedcentral.com/submit
C Biomed Central 